\title{
Impact of selected environmental factors on attendance in the Breast and Cervical Cancer Early Detection Programme in the Wielkopolska Province of Poland during 2007-2012
}

\author{
Witold Kycler' ${ }^{1}$ Anna Kubiak², Paweł Rzymski ${ }^{3}$, Maciej Wilczak³ , Maciej Trojanowski², \\ Magdalena Roszak ${ }^{4}$, Anna Włoszczak-Szubzda ${ }^{5,6}$, Izabela Rzymska \\ ${ }^{1}$ Department of Oncological Surgery, Greater Poland Cancer Centre, Poznan, Poland, Department of Head and Neck \\ Surgery, Poznan University of Medical Sciences, Poznan, Poland \\ 2 Greater Poland Cancer Registry, Greater Poland Cancer Centre, Poznań, Poland \\ ${ }^{3}$ Department of Mother's and Child's Health, University of Medical Sciences, Poznań, Poland \\ ${ }^{4}$ Department of Computer Science and Statistics, Poznan University of Medical Sciences, Poland \\ ${ }^{5}$ Department of Informatics and Health Statistics, Institute of Rural Health, Lublin, Poland \\ ${ }^{6}$ Faculty of Pedagogy and Psychology, University of Economics and Innovation, Lublin, Poland \\ ${ }^{7}$ Department of Social Sciences, University of Medical Sciences, Poznań, Poland
}

Kycler W, Kubiak A, Rzymski P, Wilczak M, Trojanowski M, Roszak M, Włoszczak-Szubzda A, Rzymska I. Impact of selected environmental factors on attendance in the Breast and Cervical Cancer Early Detection Programme in the Wielkopolska Province of Poland during 2007-2012. Ann Agric Environ Med. 2017; 24(3): 467-471. doi: 10.26444/aaem/74481

\begin{abstract}
Breast and cervical cancer represent a significant health and economic issue for Polish society, although if detected early, both can be cured successfully. For this reason, since 2006, according to the National Cancer Combat Programme, populationbased screening programmes have been implemented, aimed at reducing the mortality and morbidity for breast and cervical cancer. The aim of this study is to determine which of the selected four environmental factors affect attendance for screening mammography and cytology. Analysis included data from questionnaires filled in during mammography by 582,959 women aged 50-69 years, and 288,142 women during cytology, aged 25-59 years, in 2007-2012 in the Wielkopolska Province of Poland. It was found that the impact of medical staff on the attendance for cytological screening was the strongest statistically significant factor $(p=0,0001)$. Invitation by name $(p=0,001)$ and other factors $(p=0,0001)$ also affected the attendance. In the cytological screening, medical staff was the factor that had the greatest impact on attendance. Other factors, such as self-reporting, increased participation in the next screening rounds, although the factors that affect attendance changed over time. Their constant analysis is essential for the efficient and effective evaluation of screening programsme.
\end{abstract}

\section{Key words}

screening, breast cancer, cervical cancer

\section{- Abbreviations}

EU - European Union; FOBT - Faecal occult blood test; NHF - National Health Fund (Narodowy Fundusz Zdrowia); OECD Organization for Economic Co-operation and Development; SIMP - Electronic integrated database system for screening patient monitoring; SMS - Short Message Service

\section{INTRODUCTION}

For many years, prevention has been regarded as an effective action leading to the improve of population health and reducing the social costs resulting from treatment. Secondary prevention is the early detection of diseases, which increases the chances for their prompt and effective treatment $[1,2$, $3,4,5,6]$.

Breast and cervical cancer represents a significant health and economic issue for Polish society. Every year in Poland, over 15,000 new cases of breast cancer are registered in women, of which more than 1,500 cases are registered in the Wielkopolska Province. For cervical cancer, the total

\footnotetext{
Address for correspondence: Witold Kycler, Department of Oncological Surgery - Greater Poland Cancer Centre, Poznań, Poland

Tel.: +48618850612/ fax +48618850724

E-mail: witold.kycler@wco.pl

Received: 17 June 2017; accepted: 28 May 2014; first published: January 2017
}

is more than 3,000 cases nationwide and more than 200 in the Wielkopolska Province. Poland is a country with medium breast cancer risk, but the number of new cases is increasing and it is estimated that by 2020 , about 19,000 breast cancers will be recognized. The most important way to fight against those cancers are prophylactic examinations aimed at early detection of the disease $[3,5,6,7,8,9]$. These are mammography for breast cancer, and cytology for cervical cancer. Since 2006, according to the National Cancer Combat Programme, population-based screening programmes have been implemented to reduce mortality and the incidence of cancer, and to raise the level of women's knowledge about cancer prevention [10]. Screening mammography is addressed to women aged 50-69 years who have not had a mammogram performed within the last two years. Cytology is aimed at women aged 25-59 years who have not had a Pap smear within last the three years. Referrals are not needed for either screening mammography and cytology $[11,12]$. 


\section{OBJECTIVE}

The aim of this study was to examine the impact of selected environmental factors on the attendance in the Breast and Cervical Cancer Early Detection Programme in 2007-2012 in the Wielkopolska Province of Poland.

\section{MATERIALS AND METHOD}

For the purposes of this study, four groups of environmental factors that had a direct impact on attendance in screening programmes were specified, i.e. medical personnel (primary care physician, specialist, nurse or midwife), media (press, radio, television, Internet), invitations (SMS invitations, personal invitation received by mail), other (volunteered herself for the next test, I had information from friends, other promotional activities). The different types of factors that affect attendance for preventive mammography are a result of the way in which examinations are promoted in the Population-Based Breast Cancer Early Detection Programme and the Central and Local Screening Coordinating Units. These institutions make use of all of the methods listed in the study to promote examinations, imposed by the Ministry of Health, in conjunction with the above, and for which comparison of these factors is important in the context of discovering the greatest influence on the women's decision to participate in screening mammography. Comparison of these factors is also important in the evaluation of the programme and will allow policy makers to modify assumptions in the subsequent stages of the development of the National Cancer Combat Programme.

The analysis was applied to a group of women who performed screening mammography $(n=582,959)$ and cytology $(n=288,142)$ in the Wielkopolska Province in 2007-2012, and responded to the question about the source of information about screening. The average age in the group of women who performed a screening mammography was 59 years, and those who performed cytology - 40 years.

The authors used data contained in the questionnaire compulsorily filled by all women before performing mammography / Pap smear in the screening programme. The data were available for programme coordinators and the questionnaires archived in SIMP. The questionnaires included data on education and profession, factors that had an impact on taking part in the screening programme, as well as information about risk factors for each woman, e.g. age at first and last menstrual period, age at birth of first child, family cancer history, interview regarding breast disease, and detailed screening test result. Unfortunately, most of these data were not included in the cumulative report. The authors therefore selected the part of the data needed to carry out the aim of thesis: examination of the impact of selected environmental factors on attendance at the two programmes. The questionnaire response rate was $100 \%$.

Statistical analysis was performed by means of $\mathrm{chi}^{2}$ Pearson and Fisher-Freeman-Halton test. The $p$ values $p<0.05$ were considered statistically significant. Calculations were performed by statistical package Statistica v.10.0 (StatSoft).

\section{RESULTS}

In the Wielkopolska Province, a steady increase in the number of screening mammographies performed has been observed, from 86,251examinations in 2006 (26.30\% of the population) to $116,764(50.03 \%)$ in 2012 . In the cervical cancer screening, an increase in 2008 and 2009 followed by a decrease in subsequent was observed. Currently, the population coverage for screening cytology is $17.41 \%$.

In the group of women who performed a screening cytology, the medical staff were the major source of information that influences attendance $(n=211,732)$. Other factors mentioned were: named invitation $(n=50,035)$, 'other' $(n=15,390)$ and media $(n=10,985)$ (Tab 1$)$. In a preliminary analysis, statistically significant differences between the analyzed factors were indicated $(p=0,001)$. A statistically significant effect on participation in cervical cancer screening was found in comparison to single test variables. Further statistical analysis took into account the medical staff compared together with other factors $(n=76.410)$ [Tab. 2]. It was found that the impact of the medical staff on attendance for cytological screening was the strongest statistically significant factor in the study group $(\mathrm{p}=0,0001)$ (Tab 2).

Table 1. Number of mammography and cytology performed between 2007 - 2012 according to sources of information about screening

\begin{tabular}{|c|c|c|c|c|}
\hline \multicolumn{5}{|c|}{ Cytology $\mathbf{n}=\mathbf{2 8 8 , 1 4 2}$} \\
\hline & Medical personnel & Media & Invitations & 'Other' \\
\hline 2007 & 10,883 & 677 & 14,040 & 4,294 \\
\hline 2008 & 41,557 & 1,803 & 8,157 & 3,374 \\
\hline 2009 & 49,009 & 2,771 & 4,009 & 2,300 \\
\hline 2010 & 38,141 & 1,679 & 8,430 & 1,930 \\
\hline 2011 & 36,123 & 1,595 & 8,324 & 1,808 \\
\hline 2012 & 36,019 & 2,460 & 7,075 & 1,684 \\
\hline \multicolumn{5}{|c|}{ Mammography: $\mathbf{n}=\mathbf{5 8 2 9 5 9}$} \\
\hline & Medical personnel & Media & Invitations & 'Other' \\
\hline 2007 & 10,612 & 2,283 & 5,7225 & 16,131 \\
\hline 2008 & 9,473 & 3,835 & 3,4077 & 28,372 \\
\hline 2009 & 7,241 & 4,302 & 4,0992 & 39,949 \\
\hline 2010 & 5,044 & 2,463 & 65,588 & 32,756 \\
\hline 2011 & 4,572 & 1,459 & 73,305 & 26,516 \\
\hline 2012 & 5,053 & 2,114 & 66,847 & 42,750 \\
\hline
\end{tabular}

Table 2. Associations between medical staff influence on cervical screening attendance and individual invitations in group of women who performed a screening cytology

\begin{tabular}{lccc}
\hline Cytology & Medical personnel & Invitations & p value \\
\hline Years - \% from years & & & $<0.0001$ \\
$2007-\mathrm{n}=24923$ & $10,883(44 \%)$ & $14,040(56 \%)$ & - \\
$2008-\mathrm{n}=49714$ & $41,557(84 \%)$ & $8,157(16 \%)$ & $<0,000001$ \\
$2009-\mathrm{n}=53018$ & $49,009(92 \%)$ & $4,009(8 \%)$ & $<0,000001$ \\
$2010-\mathrm{n}=46572$ & $38,141(82 \%)$ & $8,430(18 \%)$ & $<0,000001$ \\
$2011-\mathrm{n}=44447$ & $36,123(81 \%)$ & $8,324(19 \%)$ & 0,0148 \\
$2012-\mathrm{n}=43094$ & $36,019(84 \%)$ & $7,075(16 \%)$ & $<0,000001$ \\
\hline Years - \% from source & $\mathrm{n}=21.1732$ & $\mathrm{n}=50.035$ & $<0,0001$ \\
2007 & $5.1 \%$ & $28.1 \%$ & $<0,0001$ \\
2008 & $19.6 \%$ & $16.3 \%$ & $<0,0001$ \\
2009 & $23.1 \%$ & $8 \%$ & $<0,0001$ \\
2010 & $18 \%$ & $16.8 \%$ & $<0,0001$ \\
2011 & $17.1 \%$ & $16.6 \%$ & 0,0230 \\
2012 & $17 \%$ & $14.1 \%$ & $<0.0001$ \\
\hline
\end{tabular}


In the statistical analysis considering screening cytology in various years, differences in individual factors were found. In 2007, personal invitations had the biggest impact on attendance for mammography, as well as in cytology. Table 2 shows a statistically significant difference between the invitations and the medical staff $(\mathrm{p}<0,0001)$. Medical staff had the biggest influence on screening cytology in 2008-2012 ( $\mathrm{p}=0,000001)$. This was statistically significant in comparison to the personal invitations only, and the other three factors (Tab. 3).

Table 3. Associations between medical staff and media, invitations and 'others' on attendance in the cervical screening programme in the group of women who had screening cytology performed

\begin{tabular}{lccc}
\hline Cytology & Medical personnel & $\begin{array}{c}\text { Media+invitations } \\
\text { +'others' }\end{array}$ & p value \\
\hline Years - \% from years & & & $<0.0001$ \\
$2007-\mathrm{n}=29894$ & $10,883(36 \%)$ & $19,011(64 \%)$ & - \\
$2008-\mathrm{n}=54891$ & $41,557(76 \%)$ & $13,334(24 \%)$ & $<0,000001$ \\
$2009-\mathrm{n}=58089$ & $49,009(84 \%)$ & $9,080(16 \%)$ & $<0,000001$ \\
$2010-\mathrm{n}=50180$ & $38,141(76 \%)$ & $12,039(24 \%)$ & $<0,000001$ \\
$2011-\mathrm{n}=47850$ & $36,123(75 \%)$ & $11,727(25 \%)$ & 0,0594 \\
$2012-\mathrm{n}=47238$ & $36,019(76 \%)$ & $11,727(24 \%)$ & 0,0063 \\
\hline Years $-\%$ from source & $\mathrm{n}=211732$ & $\mathrm{n}=76410$ & $<0.0001$ \\
2007 & $5.1 \%$ & $24.9 \%$ & $<0,0001$ \\
2008 & $19.6 \%$ & $17.5 \%$ & $<0,0001$ \\
2009 & $23.1 \%$ & $11.9 \%$ & $<0,0001$ \\
2010 & $18 \%$ & $15.8 \%$ & $<0,0001$ \\
2011 & $17.1 \%$ & $15.3 \%$ & $<0,0001$ \\
2012 & $17 \%$ & $14.7 \%$ & $<0,0001$ \\
\hline
\end{tabular}

In the group of women who had screening mammography performed during the analyzed period, two dominant factors affecting attendance were observed: invitations $(\mathrm{n}=338,034$; $\mathrm{p}=0,0001)$ and the so-called 'other factors', such as 'woman volunteered herself' for the next test, she had information from friends, or other promotional activities $(n=186,474$; $\mathrm{p}=0,0001$ ). The number of indications for other factors was much lower. Medical staff was indicated by 41,995 women and the media by 16,456 . In addition to these factors, a decreasing trend was observed (Fig. 1).

In the annual analysis for 2007 , the posting of personal invitations dominated $(p=0,0001)$ as a source of information about screening. Since 2008 , a steady increase was observed in the number of mammographies performed. Personal invitations and 'other' factors: volunteered herself for the next test, information from friends, and other promotional activities had the greatest impact on attendance at screening examinations. Between 2008-2009, the impact of these two factors was comparable. In 2010 and 2011, there was a decrease in 'other' factors for the invitations. In 2012, an increase in 'other' factors was observed (Tab. 4). The screening coverage of cytology and mammography screening are presented in Figures 2-3.

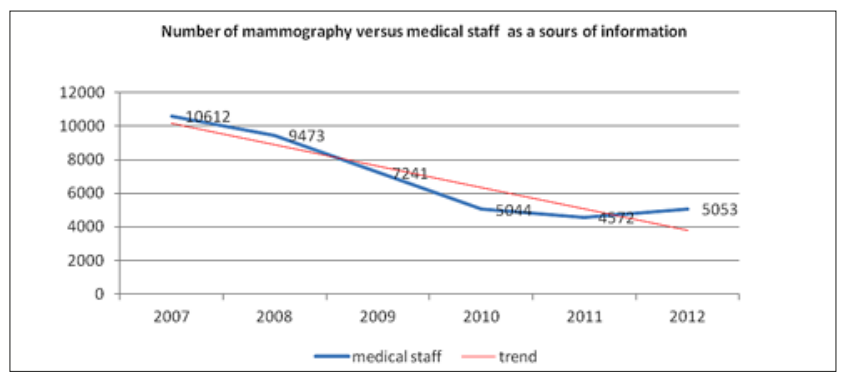

Figure 1. Number of mammography examinations with medical staff as the source of information
Table 4. Associations between individual invitations and 'others' on attendance in breast cancer screening program me in the group of women who had a screening mammography. Performed

\begin{tabular}{lccc} 
Mammography & Invitations & 'Other' & p value \\
\hline Years $-\%$ from years & & & $<0.0001$ \\
$2007-\mathrm{n}=73356$ & $57,225(78 \%)$ & $16,131(22 \%)$ & - \\
$2008-\mathrm{n}=62449$ & $34,077(55 \%)$ & $28,372(45 \%)$ & $<0,0001$ \\
$2009-\mathrm{n}=80941$ & $40,922(51 \%)$ & $39,949(49 \%)$ & $<0,0001$ \\
$2010-\mathrm{n}=98344$ & $65,588(67 \%)$ & $32,756(33 \%)$ & $<0,0001$ \\
$2011-\mathrm{n}=99821$ & $73,305(73 \%)$ & $26,516(27 \%)$ & $<0,0001$ \\
$2012 \mathrm{n}=109597$ & $66,847(61 \%)$ & $42,750(39 \%)$ & $<0,0001$ \\
\hline Years-\% from source & $\mathrm{n}=33,8034$ & $\mathrm{n}=18,6474$ & $<0,0001$ \\
2007 & $16.9 \%$ & $8.7 \%$ & $<0,0001$ \\
2008 & $10.1 \%$ & $15.2 \%$ & $<0,0001$ \\
2009 & $12.1 \%$ & $21.4 \%$ & $<0,0001$ \\
2010 & $19.4 \%$ & $17.6 \%$ & $<0,0001$ \\
2011 & $21.7 \%$ & $14.2 \%$ & $<0,0001$ \\
2012 & $19.8 \%$ & $22.9 \%$ & $<0,0001$ \\
\hline
\end{tabular}

\section{DISCUSSION}

Although there is no method of effective primary prevention in the case of breast cancer. by the mid-1980s. randomized trials showed that population-based cancer screening with the provision of mass coverage and repetition can reduce mortality from breast cancer in women by $25-45 \%[1,2]$. Research carried out in the Netherlands. Italy and Sweden has confirmed that mammography can detect breast cancer even before the clinical appearance; therefore. mammography can increase cancer survival rates $[4,5,13,14]$. For this reason. it is very important to cover as many women as possible by screening mammography $[1,16,17]$.

According to European guidelines for quality assurance in breast and cervical cancer screening and diagnosis [16]. the population coverage rates for mammography examinations and cytology are defined. and should reach a minimum of $70 \%$ (75\% for cytology) $[18,19]$.

Participation in screening examinations differs in the various European countries which have carried out population-based screening since the 1970s. In screening mammography. OECD estimated rates vary from $85 \%$ in Finland and Slovenia to $8 \%$ in Romania (EU mean - 56\%) [20]. In cervical cancer screening. the OECD estimate rates vary between $81 \%$ in Austria to 23.2\% in the Slovak Republic (EU mean - 62.1\%) [20]. In Poland. which has recently started population-based screening. participation in the programme is low according to the population registered who participated (not estimated) [21, 22]. In the group of patients in the Wielkopolska Province. the registered coverage of the population was $50.03 \%$ for breast cancer screening and $17.41 \%$ for cervical cancer screening 2012. These statistics could have been strongly influenced by the private sector cytology service not included in the national screening.Usually. women undergo cytological examination every year. In the Zachodnio-Pomorskie Province. the actual average screening rate for cytology in 2007-2010 was $24.1 \%$. [27].

The third cancer screening programme recommended by the EU is colorectal cancer screening. with the most common screening methods being. for example. a faecal occult blood test (FOBT) in Germany. and colonoscopy in Poland. Because of technical and financial problems with using colonoscopy as a population-based screening. the participation rates for colorectal screening are very different in the EU. from 54\% 
in Germany to $1.9 \%$ in Romania (EU mean - $12.7 \%$. in Poland - 3.5\%) [20].

In 2007. for the first time. the National Health Fund (NFZ) carried out the posting of personal invitations which covered the entire population intended for mammography and cytology examinations. A total of 224,922 invitations for mammography and 546,131 for cytology were sent. Questionnaires for women on whom screening examinations were performed. showed that named invitations has a positive influence on attendance: 57,225 (66\%) for mammography and $14,040(47 \%)$ for cytology of the women indicated that they had the screening examination performed after receiving the personal invitation. This is also confirmed by test results in other countries $[15,24]$. In the subsequent year. a decrease in attendance was observed - by $21 \%$ in mammography and $32 \%$ in cytology. Since 2009. the Ministry of Health has provided the posting of the invitations to Local Screening Coordinating Units. since when an increase has been observed in mammography examinations from $44 \%$ $62 \%$ in 2010 and $69 \%$ in 2011. European research confirms that screening programmes based on posted invitations are more effective than the so-called 'spontaneous' screening [13]. Effective policy related to the organization of posting the personal invitations is as important as the quality of the screening performed $[25,26]$.

In 2012. a decrease was observed in named invitations by $12 \%$. compared to other factors (i.e. volunteered herself for the next test. information from friends. other promotional activities). This is probably due to women reporting voluntarily for further screening examinations. and had developed the habit of performing a mammography every two years and did not need an invitation.

It is an alarming fact that the involvement of medical personnel in referring women for screening mammography declined from the highest level of $13 \%$ in 2008 to $4 \%$ between 2011 - 2012 (Fig. 3). Research shows that women now expect this referral from the doctors (especially general practitioners).

Despite the increasing involvement of the media in health issues and preventive care. they have almost no impact on attendance for both mammography and cytology examinations. This is believed to be due to the lack of personalized communication and great chaos in the transmitted information. This could result from the role of the media in prophylactics being different and should prepare the basic knowledge about breast cancer as a disease and its prevention. and influence society by imitation behaviour. This does not change the fact that one of the tasks of the Coordinating Units is to publish invitations for women in the media. The result is that the media is a tangible tool in the implementation of screening.

There is lack of clear distinction between screening mammography and diagnostic mammography. which generates the confusing information that mammography should be performed every year.

In cytological screening. a very large part of the medical staff. especially specialists in inviting women. is observed: $76 \%$ in 2008, 2010, 2011 and 2012. and in 2009 increased to $84 \%$. At this juncture. it should be noted that a contract to implement a screening programme is an additional agreement signed by leading gynecologists in private practice. Gynecologists therefore offer screening cytology for their patients who visit them for other reasons.
Despite the annual dispatch of invitations covering 100\% of the population. only about $15 \%$ of women. on average. admit that they participated in screening due to the receipt of an invitation. This percentage is very different from that in screening mammography. which may be caused by the availability of the screening. Invitations are not an effective method to increase the number of women to have a cytology examination performed.

Diagnostic mammography is an X-ray examination which requires referral and the number of tests available in the system is limited. which sometimes results in women having to wait a few months for a preventive mammogram (outside the screening programme) to be performed. Within the screening programme. the number examinations is not limited by the National Health Fund $[3,11,12]$ and providers are assured that every examination will be financed. Therefore. there are no queues for screening and examination is performed on the day of registration. The lack of necessity for a referral and the convenient time of examination encourages more women to perform mammography within the screening program.

Cytology is a study with relatively simple requirements and no special equipment needed. although a referral is needed. It is performed by gynecologists during routine testing. In Poland. a large proportion of cytological studies are performed by doctors practicing privately or are under contract with the NHF in the so-called specialized or complex medical advice (outside the cervical screening programme) $[25,26]$. A report by the NHF shows exactly the number of women aged 25-59 years whose cytology was financed on medical advice in the second half of 2011. but were not reported in the electronic integrated database (SIMP). This number amounted to 52,312 (35.21\% of the population) compared with 23.001 (15.48\%) within the screening programme. which is a population coverage of $50.70 \%$ !

\section{CONCLUSIONS}

In cytological screening. medical staff is the factor having the greatest impact on attendance.

In mammography screening. personal invitations are the factor having the greatest influence on attendance. with increased participation of 'other' factors. such as selfreporting for the next screening rounds.

Environmental factors that affect the attendance have changed over time. Their constant analysis is essential for efficient and effective evaluation of screening programmes.

\section{REFERENCES}

1. Boyle P. Lewin B. World Cancer Report. Lyon International Agency for Research on Cancer. 2008.

2. Verdecchia A. Francisci S. Brenner H. Gatta G. Micheli A. Mangone L et al. Recent: cancer survival in Europe: a 2000-02 period analysis of EUROCARE-4 data. Lancet Oncol. 2007; 8(9): 784-96.

3. Globocan database 2008 (http://globocan.iarc.fr/) (access: 2013.02.05).

4. Petra T. Breast cancer in the elderly-Should it be treated differently? Rep Pract Oncol Radiother. 2013; 18(1): 1-5.

5. Waller J. Bartoszek M. Marlow L. Wardle J. Barriers to cervical cancer screening attendance in England: a population-based survey. J Med Screen. 2009; 16(4): 199-204.

6. Kazmierska J. Assessment of health status in elderly patients with cancer. Rep Pract Oncol Radiother. 2013; (18): 44-48.

7. Otto SJ. Fracheboud J. Verbeek AL. Boer R. Reijerink-Verheij JC. Otten JD et al. Mammography Screening and Risk of Breast cancer Death: A 
Population-based Case -Control study cancer. Epidemiol Biomarkers Prev. 2012; 21(1): 66-73.

8. Dyzmann-Sroka A. Myślińska W. Olenderczyk W. Plucińska A. Rymarczyk-Wciorko M. Szczęch B et al. Nowotwory złośliwe w Wielkopolsce w 2010 roku. Poznań Wielkopolskie Centrum Onkologii 2012.

9. Krajowy Rejestr Nowotworów http://85.128.14.124/krn/ (access 2013.02.05)

10. Pieta B. Chmaj-Wierzchowska K. Opala T. Life style and risk of development of Brest and ovarian cancer. Ann Agric Environ Med. 2012; 19(3): 379-384.

11. Ustawa z dnia 1 lipca 2005 r. o ustanowieniu programu wieloletniego Narodowy program zwalczania chorób nowotworowych. Dz. U. 08.54.325.

12. Zarzadzenie nr 11/2010/ DSOZ Prezesa NFZ z dnia 29 stycznia 2010.

13. Giordano L. von Karsa L. Tomatis M. Majek O. de Wolf C. Lancucki L et al. Mammography screening programmes In Europe: organization. coverage and participation. J Med Screen. 2012. 19(1); 72-82.

14. Tacken MA. Braspenning JC. Hermens RP. Spreeuwenberg PM. van den Hoogen HJ. de Bakker DH et al. Uptake of cervical cancer screening in The Netherlands is mainly influenced by women's beliefs about the screening and by the inviting organization. Eur J Publ Health. 2007; 17(2): 178-185

15. Giordano L. von Karsa L. Tomatis M. Majek O. Wolf Ch. Lancucki L et al. Mammography screening programmes in Europe: organization. coverage and participation. J Med Screen. 2012; 19(1): 72-82.

16. Rossi PG. Camillowi L. Cogo C. Federici A. Furnari G. Giordano L et al Methods to increase participation in cancer screening programmes. Epidemol Prev. 2012; 36(1): 1-104.

17. Matkowski R. Szynglarewicz B. First report of introducing populationbased breast cancer screening in Poland: Experience of the 3-million population region of Lower Silesia. Cancer Epidemiology. 2011; 35 (6): 111-115.

18. Perry N. Broeders M. de Wolf C. Törnberg S. Holland R. Karsa L. European guidelines for quality assurance in breast cancer screening and diagnosis. 4th ed. Luxembourg Office for Official Publications of the European Communities. 2006.
19. Arbyn A, Anttila J, Jordan G, Ronco U, Schenck N, Segnan H et al. European guidelines for quality assurance in cervical cancer screening Second Edition 2008. 2nd ed. Luxembourg Office for Official Publications of the European Communities. 2008.

20. OECD Health Data 2012; Eurostat Statistics Database.

21. Bojar I. Cvejić R. Głowacka M. Koprowicz A. Humeniuk E. Owoc A. Morbidity and mortality due to cervical cancer in Poland after introduction of the Act - National Programme for Control of Cancerous Diseases. Ann Agric Environ Med. 2012; 19(4): 680-685.

22. Krzyzak M. Maslach D. Juczewska M. Lasota W. Rabczenko D. Marcinkowski J. et al. Differences in breast cancer incidence and stage distribution between urban and rural female population in Podlaskie Voivodship. Poland in years 2001-2002. Ann Agric Environ Med. 2010; 17(1): 159-162.

23. Banks E. Richardson A. Beral V. Crossley B. Simmonds M. Hilton E et al. Effect on attendance at Brest cancer screening of adding a self administered questionnaire to the usual invitation to Brest screening In southern England. J Epidemiol Community Health. 1998; 52(2): 116-119.

24. Antilla A. Ronco G. Working Group on the Registration and monitoring of Cervical Cancer Screening Programmes in the European Union; within the European Network for Information on Cancer (EUNICE). Description of the national situation of cervical cancer screening in the member states of the European Union. Eur J Cancer. 2009; 45(15): 2685-2708.

25. Spaczyński M. Karowicz-Bilińska A. Rokita W. Molińska-Glura M. Januszek-Michalecka L. Seroczyński P et al. Attendance rate in the polish cervical cancer screening program In the year 2007-2009. Ginekol Pol. 2010; 81(9): 655-663.

26. Spaczyński M. Nowak-Markwitz E. Januszek-Michalecka L. KarowiczBilińska A. Women's social conditions and their participation In Cervical cancer population screening program in Poland. Ginekol Pol. 2009; 80(11): 833-838.

27. Owoc A. Cveic R. Koprowicz A. Sygit K. Frontczak A. Bojar I. Reporting rates for cervical screening in the Szczecin Region during the period 2007-2010 Ann Agric Environ Med 2012; 19: 4.686-91 